\title{
PODER LOCAL E SOCIOAMBIENTALISMO: A RELAÇÃO ENTRE O CIDADÃO E O MEIO AMBIENTE
}

\author{
Laura Covatti dos Santos* \\ Janaina Rigo Santin ${ }^{* * *}$
}

Resumo: Este artigo objetiva analisar a reconstrução do espaço público a partir da criação de cidades sob a perspectiva da sustentabilidade. O problema de pesquisa questiona: Como evitar os riscos ambientais nas cidades e conscientizar os cidadãos das consequências das práticas de consumo? Utilizando-se do método dedutivo e da revisão bibliográfica, a pesquisa visa investigar a relação entre o comportamento humano e o meio ambiente, bem como examinar a importância do desenvolvimento de gestores conscientes para incentivar o empoderamento local sustentável. Por fim, avaliar os resultados da educação ambiental voltada às crianças e jovens nos municípios.

Palavras-chave: Educação ambiental; poder local; políticas públicas; ser humano; sociedade de consumo.

\section{LOCAL AND SOCIO-ENVIRONMENTAL POWER: THE RELATIONSHIP BETWEEN THE CITIZEN AND THE ENVIRONMENT}

\begin{abstract}
This article aims to analyze the reconstruction of the public space from the creation of cities from the perspective of sustainability. The research problem asks: How to avoid environmental risks in cities and make citizens aware of the consequences of consumer practices? Using the deductive method and the literature review, the research aims to investigate the relationship between human behavior and the environment, as well as examine the importance of developing conscious managers to encourage sustainable local empowerment. Finally, to evaluate the results of environmental education aimed at children and young people in the municipalities.
\end{abstract}

Keywords: Environmental education; local power; public policy; human being; consumer society.

\footnotetext{
* Mestranda do Programa de Pós-Graduação em Direito pela Universidade de Passo Fundo/RS, linha de pesquisa Relações Sociais e Dimensões do Poder. Bolsista UPF. Integrante do grupo de pesquisa Dimensões do Poder e Relações Sociais. Integrante do grupo de estudos das Obras de Hannah Arendt. Advogada. Conciliadora voluntária no Juizado Especial Cível, posto UPF, Passo Fundo/RS. Pós-graduada em Direito Civil-Direito de Família Avançado pela Faculdade Anhanguera de Passo Fundo/RS. Graduada em Ciências Jurídicas e Sociais pela Faculdade Anhanguera de Passo Fundo/RS. Endereço postal: Rua Eduardo de Brito, $\mathrm{n}^{\circ}$ 111, Centro, CEP 99010-180, Passo Fundo/RS, Brasil. Endereço eletrônico: lauracovattidossantos@ gmail.com.

* Pós Doutora em Direito Administrativo pela Universidade de Lisboa, Portugal, com apoio CAPES. Doutora em Direito pela Universidade Federal do Paraná. Mestre em Direito pela Universidade Federal de Santa Catarina. Advogada e Professora Titular II da Universidade de Passo Fundo. Docente permanente do Programa de Mestrado em Direito e do Doutorado e Mestrado em História da Universidade de Passo Fundo/RS. Professora colaboradora do Mestrado em Ciências Jurídicas-Econômicas e Desenvolvimento e do Mestrado em Governação e Gestão Pública da Universidade Agostinho Neto, em Luanda, Angola-África. Endereço postal: Rua Rio Branco, $\mathrm{n}^{\circ}$ 138, ap. 501, Vila Rodrigues, CEP 99070-080, Passo Fundo/RS, Brasil. Endereço eletrônico: janainars@upf.br
}

Revista de Direito Ambiental e Socioambientalismo | e-ISSN: 2525-9628 | Porto Alegre | v. 4 | n. 2 | p. $19-37$ | Jul/Dez. 2018 


\section{INTRODUÇÃO}

O comportamento humano está intimamente ligado aos danos causados ao meio ambiente, isso porque os recursos naturais vêm sendo utilizados em demasia, sem respeitar a sua capacidade de renovação. Da mesma forma, a prática do consumo desenfreado e a facilidade com que ele ocorre na atualidade gera uma imensidão de resíduos, para os quais não há uma solução sustentável nem a curto nem a longo prazo.

A presente pesquisa tem como objetivo analisar a reconstrução do espaço público a partir da sustentabilidade, aproximando gestores e cidadãos para pensar de forma coletiva nas melhores soluções para tornar a cidade um lugar melhor para se viver. Para isso, a presente pesquisa foi dividida em três tópicos, sendo que, num primeiro momento, será investigada a relação entre o cidadão e o meio em que vive. Na sequência, o segundo tópico examinará a importância da descentralização do poder e da participação popular para o desenvolvimento de ambientes sustentáveis. Por fim, avaliam-se os resultados de inclusão de políticas ambientais direcionadas para a educação de crianças e jovens, a fim de cultivar a cultura da participação, da preservação e da sustentabilidade em todas as áreas das relações sociais.

Utilizando-se do método dedutivo e da revisão bibliográfica, com suporte na legislação brasileira, doutrinas, meios eletrônicos e publicações científicas, a problemática sugerida indaga: Como evitar os riscos ambientais nas cidades e conscientizar os cidadãos das consequências das práticas desenfreadas de consumo? Trata-se de um tema atual que busca alertar a sociedade de consumidores, para que sejam conscientes de seus atos, e os gestores, para incentivarem a educação de crianças e jovens a partir das práticas sustentáveis.

Educar as crianças e jovens é uma estratégia interessante, pois eles serão os adultos de amanhã e precisarão aprender a agir de forma organizada, responsável, inteligente e democrática, independentemente do lugar que estarão. O primeiro contato de uma criança é com a sua família e a sua referência de habitat a sua casa, a sua rua, para posteriormente começar a ter convívio com colegas da escola reconhecendo o caminho até esse lugar e tantos outros que frequenta.

Ter esse reconhecimento do lugar em que vive mostra-se essencial para saber valorizar e ter inúmeros cuidados com o ambiente. Daí surge o Poder Local - seja a rua ou o 
bairro -, as cidades e os municípios, todos como figuras que emanam poder e também empoderam àqueles que neles residem para que lutem em prol do bem-estar e da convivência pacífica em coletividade.

Nessa perspectiva, acredita-se que as políticas públicas educacionais são um progresso para as cidades, principalmente no tocante à concretização das diretrizes legais ambientais. A partir disso, os municípios terão como meta educar os indivíduos, especialmente crianças e jovens, para ir ao encontro de um meio sustentável, em benefício da natureza e das futuras gerações, que receberão o resultado do que vem sendo praticado nos dias de hoje pelas presentes gerações.

\section{OS REFLEXOS DA CONDUTA HUMANA NO MEIO AMBIENTE}

Desde os primórdios da civilização o ser humano pratica e recebe atos violentos, tratando-se de uma peculiaridade da sua própria essência (GORCZEVSKI, 2010, p. 34). A partir disso, entende-se que a pessoa simplesmente nasce com esse instinto agressivo, sendo uma característica própria do ser humano, afinal, não há escolha em ser ou não violento.

O cidadão e a sua conduta são responsáveis pelo ambiente em que se vive hoje, seja com relação à produção de coisas, plantação e colheita ou também no meio político. $\mathrm{Na}$ verdade, a vida humana está subordinada à presença de outros indivíduos, tornando-se imprescindível que as suas ações sejam assistidas por outros membros do grupo social (ARENDT, 2007, p. 31).

De acordo com Freud a “[...] nossa civilização é em grande parte responsável por nossa desgraça e que seríamos muito mais felizes se a abandonássemos e retornássemos às condições primitivas [...]”, aliás, parece contraditório afirmar que todas as coisas e situações que o ser humano tenta evitar integra a sociedade (1997, p. 38).

Seguindo esse raciocínio, Freud questiona a expectativa dos indivíduos em viver e aonde pretendem chegar para na sequência responder que, considera-se o objetivo primordial dos atores sociais a "felicidade". Ao mesmo passo adverte que, aparentemente, há certeza em dizer que os tempos contemporâneos parecem não satisfazer os anseios sociais, embora não se possa concluir se o nível de felicidade dos antigos tenha sido superior aos de hoje (1997, p. $23-24 ; 40)$. 
Na concepção de Aristóteles, (2004, p. 57), “[...] o homem feliz vive bem e age bem; pois definimos praticamente a felicidade como uma espécie de boa vida e boa ação [...]”, afirma. Aliás, há quem reconheça a felicidade ${ }^{1}$ por meio de algumas especificidades tais como: a "virtude", a "sabedoria prática", a "sabedoria filosófica", estando acompanhadas em conjunto ou individualmente pela sensação do prazer ou não. (ARISTÓTELES, 2004, p. 57).

Pelo exposto, verifica-se a conexão entre o indivíduo e o ambiente em que habita, de modo que, os atos por ele praticados são responsáveis por gerar efeitos positivos ou negativos, os quais, por vezes, justificam-se em razão da busca pela felicidade ${ }^{2}$. Em síntese, significa dizer que a imprudência da conduta humana tende a surtir resultados indesejáveis, abalando o equilíbrio e a qualidade de vida dos cidadãos, inclusive no tocante ao meio ambiente.

Em decorrência da evolução dos tempos e, consequentemente, do ser humano, o século XXI exibe progressos em inúmeros quesitos como, por exemplo, nas áreas tecnológicas, industriais, entre outros. Contudo, os danos ambientais advindos do comportamento humano podem ser considerados como um dos maiores desafios da atualidade a serem superados. Dessa forma, a ciência passou a compreender que o planeta Terra testemunha o surgimento de uma nova era geológica: o Antropoceno. Embora o termo tenha surgido em um ambiente científico, sua adoção passou a ser intensiva e extensivamente usada em outras áreas do conhecimento como filosofia, sociologia, comunicação e direito, apenas para citar alguns (RULL, 2017).

Trata-se de uma época em que o ser humano passa a ser tido como agente geológico capaz de moldar a paisagem global e a evolução da Terra, transformando a biosfera pela força da ação humana, que passa a prevalecer sobre as forças geradoras das dinâmicas da natureza. Trata-se de um conceito que já vem sendo estudado desde o século XIX, com o geólogo italiano Antonio Stoppani, e tinha outras denominações, como o termo "era antropozóica", todas buscando configurar as alterações decorrentes do aumento da quantidade de dióxido de carbono e outros gases estufa na atmosfera da Terra, iniciadas na segunda metade do século

\footnotetext{
1 "Todo o discurso sobre as necessidades assenta numa antropologia ingénua: a da propensão natural para a felicidade. [...] a felicidade constitui a referência absoluta da sociedade de consumo, revelando-se como o equivalente autêntico da salvação. Mas, que felicidade é esta? Que assedia com tanta força ideológica a civilização moderna?" (BAUDRILLARD, 1995, p. 47, grifo do autor).

${ }_{2}^{2}$ Para Bauman, "Que os seres humanos sempre preferiram a felicidade à infelicidade é uma observação banal, um pleonasmo, já que o conceito de 'felicidade' em seu uso mais comum diz respeito a estados ou eventos que as pessoas desejam que aconteçam, enquanto a 'infelicidade' representa estados ou eventos que elas querem evitar. Os dois conceitos assinalam a distância entre a realidade tal como ela é e uma realidade desejada" (2008, p. 58-59).
} 
XVIII com o início da revolução industrial. Porém, tais transformações passam por sua agudização neste século XXI, em especial com o crescimento da população e da exploração per capta dos recursos do planeta. As consequências são, entre outras, chuva ácida, "smog" fotoquímico e aquecimento climático. Assim, de acordo com as últimas estimativas do IPCC, a Terra aquecerá entre 1,4 e $5,8^{\circ} \mathrm{C}$ durante este século (CRUTZEN, 2017). Dessa forma, é preciso repensar as possíveis consequências da pressão descontrolada da ação humana sobre a natureza e a necessidade de reconsiderar a relação humana com o planeta.

Nesse sentido, a Constituição Federal de 1988 em seu artigo 225 dispõe do direito dos cidadãos a um meio ambiente que propicie o bem-estar às atuais e futuras gerações (BRASIL, CONSTITUIÇÃO FEDERAL, 1988). No entanto, para que isso ocorra, tanto o Poder Público quanto a comunidade devem atuar conjuntamente em prol da sua defesa e conservação $^{3}$, pois como explica Sen:

Todos nós reconhecemos, hoje em dia, que nosso meio ambiente é atacado com facilidade. Danificamos rotineiramente a camada de ozônio, aquecemos o globo, poluímos o ar e os rios, destruímos as florestas, esvaziamos os recursos minerais, levamos várias espécies à extinção e causamos outros tipos de devastação $(2010$, p. 64).

Nessa contextualização, certifica-se que o agir humano tem intensificado os prejuízos ao meio ambiente, capazes de inaugurar uma nova era geológica, o Antropoceno. Logo, importa investigar a origem dessa relação conturbada. Como já foi mencionado, o comportamento do indivíduo está intimamente ligado às consequências sofridas pela natureza, e o problema aumenta quando o consumo exacerbado, motivado pela ganância e pelo poder, passa a prejudicar o ciclo da vida, envolvendo a sociedade e o ambiente como um todo.

O simples ato de consumir parece inofensivo, por naturalmente integrar o cenário capitalista e econômico atual. Ou seja, compram-se eletrodomésticos, roupas, utensílios para a casa, além de ter outros investimentos ligados à vida pessoal e profissional dos indivíduos. Contudo, o consumo ${ }^{4}$ acaba criando um vínculo entre a coisa a ser adquirida e o comprador, por isso Santin explica:

\footnotetext{
${ }^{3}$ Constituição Federal: Art. 225 - Todos têm direito ao meio ambiente ecologicamente equilibrado, bem de uso comum do povo e essencial à sadia qualidade de vida, impondo-se ao Poder Público e à coletividade o dever de defendê-lo e preservá-lo para as presentes e futuras gerações.

${ }^{4}$ Segundo Bauman, "Aparentemente, o consumo é algo banal, até mesmo trivial. É uma atividade que fazemos todos os dias, por vezes de maneira festiva, ao organizar um encontro com os amigos, comemorar um evento importante ou para nos recompensar por uma realização particularmente importante - mas a maioria das vezes é
} 
O consumo põe idealmente o objeto da produção como necessidade. Assim, numa visão fantasiosa do processo real, a produção não cria somente um objeto para o sujeito, mas também um sujeito para o objeto. Isso significa que, aqueles que decidem o que será produzido pela sociedade, decidem também o que será desejado por ela (2017, p. 172).

Para Arendt o trabalho e o consumo compõem a sociedade de consumidores, pois as pessoas laboram na tentativa de suprir as necessidades da vida (2007, p. 138-139). Seguindo esse raciocínio, Bauman esclarece que o período inicial da prática do consumo se dá a partir da infância, independentemente de gênero e idade, pois “[...] Numa sociedade de consumidores, todo mundo precisa ser, deve ser e tem que ser um consumidor por vocação (ou seja, ver e tratar o consumo como vocação) [...]” (2008, p. 73, grifo do autor), alerta.

[...] De maneira distinta do consumo, que é basicamente uma característica e uma ocupação dos seres humanos como indivíduos, o consumismo é um atributo da sociedade. Para que uma sociedade adquira esse atributo, a capacidade profundamente individual de querer, desejar e almejar deve ser, tal como a capacidade de trabalho na sociedade de produtores, destacada ('alienada') dos indivíduos e reciclada/reificada numa força externa que coloca a 'sociedade de consumidores' em movimento e a mantém em curso como uma forma específica de convívio humano, enquanto ao mesmo tempo estabelece parâmetros específicos para as estratégias individuais de vida que são eficazes e manipula as probabilidades de escolha e conduta individuais (BAUMAN, 2008, p. 41, grifo do autor).

Diante disso, constata-se que as relações sociais antigas e contemporâneas são mantidas pelo poder de consumir, afinal, como afirma Marina, "[...] el poder no es enemigo de la libertad, sino fuente y apremio de ella" (2009, p. 14). Nota-se que o poder do consumo exerce influência na convivência cotidiana da coletividade, agregando riquezas para algumas pessoas - ao adquirirem coisas e outras ao produzirem visando o lucro ${ }^{5}$.

É legítimo, portanto, afirmar que a era do consumo, em virtude de constituir o remate histórico de todo o processo de produtividade acelerada sob o signo do capital, surge igualmente como a era da alienação radical. Generalizou-se a lógica da mercadoria, que regula hoje não só os processos de trabalho e os produtos materiais, mas a cultura inteira, a sexualidade, as relações humanas e os próprios fantasmas e

de modo prosaico, rotineiro, sem muito planejamento antecipado nem reconsiderações. [...] é uma condição, e um aspecto, permanente e irremovível, sem limites temporais ou históricos; um elemento inseparável da sobrevivência biológica que nós seres humanos compartilhamos com todos os outros organismos vivos [...]" (2008, p. 37).

${ }^{5}$ Para Latouche, "Nosso crescimento econômico excessivo choca-se com os limites da finitude da biosfera. A capacidade de regeneração da Terra já não consegue acompanhar a demanda: o homem transforma os recursos em resíduos mais rápidos do que a natureza consegue transformar esses resíduos em novos recursos” (2009. p. 27 , grifo do autor).

Revista de Direito Ambiental e Socioambientalismo | e-ISSN: 2525-9628 | Porto Alegre | v. 4 | n. 2 | p. 19 - 37 | Jul/Dez. 2018 
pulsões individuais. Tudo foi reassumido por esta lógica, não apenas no sentido de que todas as funções, todas as necessidades se encontram objectivadas e manipuladas em termos de lucro, mas ainda no sentido mais profundo de que tudo é espectacularizado, quer dizer, evocado, provocado, orquestrado em imagens, em signos, em modelos consumíveis (BAUDRILLARD, 1995, p. 205, grifo do autor).

A conduta humana influencia significativamente no meio ambiente, de modo que, o desejo pelo poder e abundância financeira são fatores determinantes para o aumento das práticas poluentes. Em decorrência disso, o progresso civilizatório estimula o consumo ${ }^{6}$, fazendo com que o cidadão crie expectativas de adquirir novas coisas, produtos ou serviços.

Portanto, a fim de evitar a continuidade dos impactos ambientais e incentivar os cidadãos a refletirem sobre os efeitos negativos do consumo exacerbado, atenta-se para a necessidade de atuação do Poder Público em prol da conservação do meio ambiente.

\section{CIDAdES SUSTENTÁVEIS EM PROL DA REDUÇÃO DOS RISCOS AMBIENTAIS}

A prática do consumo resume-se em uma das atividades cotidianas dos indivíduos. No entanto, acarreta consequências tendenciosas a agravar o desequilíbrio ambiental como, por exemplo, o acúmulo de lixo originado do descarte de objetos, a poluição atmosférica com a utilização dos meios de transporte, a poluição sonora em razão dos ruídos sem moderação, o aquecimento global e o efeito estufa, decorrente da emissão de $\mathrm{CO} 2$ em demasia na atmosfera, dentre outros.

No contexto urbano metropolitano brasileiro os problemas ambientais têm se avolumado a passos agigantados e a sua lenta resolução tem se tornado de conhecimento público pela virulência do seu impacto - aumento desmesurado de enchentes, dificuldades na gestão dos resíduos sólidos e interferência crescente do despejo inadequado de resíduos sólidos em áreas potencialmente degradáveis em termos ambientais, impactos cada vez maiores da poluição do ar na saúde da população (JACOBI, 1999, p. 44).

Cumpre ressaltar, a Constituição Federal de 1988, em seu artigo 225, prevê que cabe ao ente estatal e aos sujeitos sociais preservarem e conservarem o meio ambiente em que habitam, seja em benefício da sua própria qualidade de vida como também das próximas gerações (BRASIL, CONSTITUIÇÃO FEDERAL, 1988). Efetivamente, essencial criar

\footnotetext{
6 “[...] No mundo, a produção acumulada, bem como o padrão de vida medida em bens materiais e serviços aumentou para um grande número de pessoas. Mas, atualmente a situação do capitalismo é volátil, porque aumentou as desigualdades sociais e de classe, numa economia global” (HARVEY, 2011. p. 54).
}

Revista de Direito Ambiental e Socioambientalismo | e-ISSN: 2525-9628 | Porto Alegre | v. 4 | n. 2 | p. 19 - 37 | Jul/Dez. 2018 
alternativas viáveis para conscientizar as pessoas quanto ao controle das suas relações sociais pautadas no consumo e no esgotamento dos recursos não renováveis, as quais tem propensão a aumentar os riscos ambientais.

A partir disso, Santin apresenta a força do Poder Local como um "[...] amplo espaço público de descentralização e participação democrática em nível municipal ou regional" (2017, p. 153). Trata-se de valorizar as atribuições municipais ou regionais, eis que quanto “[...] mais próximo do cidadão, [...] mais factível de ser democratizado e de oportunizar uma maior participação da comunidade", refere a autora (2017, p. 153).

Para Jacobi, há "[...] necessidade de estimular uma participação mais ativa da sociedade no debate dos seus destinos, como uma forma de estabelecer um conjunto socialmente identificado de problemas, objetivos e soluções [...]” (1999, p. 43). A iniciativa de reconstruir o espaço público pelo Poder Local tende a surtir efeitos positivos, pois governantes e governados aparentemente terão mais facilidade de manter o diálogo. Sobre essa questão, Hermany e Rodembusch alertam:

A descentralização e a municipalização, como estratégia de consolidação democrática, estão sempre ligadas à participação e mostram que a força da cidadania está no Município. É no Município que o cidadão nasce, vive, constrói sua história. É no Município que o cidadão fiscaliza e exercita o controle social. O Município é, de fato, a entidade político-administrativa que oferece melhores condições para a prática da participação popular na gestão da vida pública. Havendo mais proximidade, existe mais facilidade de comunicação e de interação: as ações e as intenções do governo são percebidas e acompanhadas diretamente pela população (2010, p. 86).

O âmbito local ${ }^{7}$ vem se desenvolvendo constantemente, abrindo novos caminhos e propondo técnicas de gestão inovadora e participativa, como exemplo Dowbor cita as tecnologias de informação que objetivam a transparência, bem como a "limpeza pública", a qual:

[...] está igualmente despontando uma nova geração de tecnologias, envolvendo a participação do cidadão na separação do lixo limpo e as diversas formas de

\footnotetext{
7 “A problemática da sustentabilidade assume, neste final de século, um papel central na reflexão em torno das dimensões do desenvolvimento e das alternativas que se figuram para garantir eqüidade e articular as relações entre o global e o local. [...] A organização democrática do poder local assume cada vez mais um espaço central numa agenda que contemple a necessária articulação não só entre atores, mas entre políticas” (JACOBI, 1999, p. $39)$.
}

Revista de Direito Ambiental e Socioambientalismo | e-ISSN: 2525-9628 | Porto Alegre | v. 4 | n. 2 | p. $19-37$ | Jul/Dez. 2018 
reciclagem que isso permite: compostagem, produção de energia, reaproveitamento de diversos produtos (2008, p. 43-44).

Logo, percebe-se que a participação popular não está condicionada apenas ao direito de votar, isso porque a mesma se expande democratizando outras áreas que não somente as políticas e sociais, como também as ambientais. Para isso, o Estatuto da Cidade ${ }^{8}$ complementa as disposições constitucionais a respeito da política de desenvolvimento urbano, buscando trazer segurança e bem-estar a todos. Segundo Demo,

[...] Dizemos que participação é conquista para significar que é um processo, no sentido legítimo do termo: infindável, em constante vir-a-ser, sempre se fazendo. Assim, participação é em essência autopromoção e existe enquanto conquista processual. Não existe participação suficiente, nem acabada. Participação que se imagina completa, nisto começa a regredir (1993, p. 18).

Significa dizer que o cidadão possui a oportunidade de participar da gestão democrática da cidade, estando amparado legalmente pelo Estatuto da Cidade. ${ }^{9}$ Com a finalidade de garantir aos indivíduos o acesso às cidades sustentáveis, essa Lei dispõe de direitos pautados na urbanização para tornar a vida em sociedade mais saudável e próspera. ${ }^{10}$

Seguindo esse raciocínio, Dowbor valoriza o empoderamento local e expõe uma pergunta imprescindível a ser realizada para todos os municípios: “[...] quais são os recursos disponíveis e como estão sendo utilizados"? (2008, p. 60). Esse questionamento estimula a reflexão, pois a utilização de inúmeros recursos naturais em benefício da qualidade de vida da comunidade, por vezes, acaba extrapolando os seus limites e gerando transtornos ambientais.

Aliás, um dos recursos utilizados pela sociedade de extrema importância para a sobrevivência humana é a água. Planejar o seu aproveitamento mostra-se relevante e adequado, seja para evitar a transmissão de doenças quando ingerida com poluentes ou para

\footnotetext{
${ }^{8}$ Lei no 10.257/2001: Art. $1^{\circ}$ - [...] Parágrafo único. Para todos os efeitos, esta Lei, denominada Estatuto da Cidade, estabelece normas de ordem pública e interesse social que regulam o uso da propriedade urbana em prol do bem coletivo, da segurança e do bem-estar dos cidadãos, bem como do equilíbrio ambiental.

${ }^{9}$ Lei no 10.257/2001: Art. 43 - Para garantir a gestão democrática da cidade, deverão ser utilizados, entre outros, os seguintes instrumentos: I - órgãos colegiados de política urbana, nos níveis nacional, estadual e municipal; II - debates, audiências e consultas públicas; III - conferências sobre assuntos de interesse urbano, nos níveis nacional, estadual e municipal; IV - iniciativa popular de projeto de lei e de planos, programas e projetos de desenvolvimento urbano;

${ }^{10}$ Lei $\mathrm{n}^{\mathrm{o}}$ 10.257/2001: Art. $2^{\mathrm{o}}$ - [...] I - garantia do direito a cidades sustentáveis, entendido como o direito à terra urbana, à moradia, ao saneamento ambiental, à infra-estrutura urbana, ao transporte e aos serviços públicos, ao trabalho e ao lazer, para as presentes e futuras gerações;
} 
fiscalizar o seu uso, a fim do ser humano não cometer exageros que tornem os danos ambientais irreversíveis (DOWBOR, 2008, p. 62).

Confirma-se a iniciativa positiva de vários municípios brasileiros em acreditar na força de se desenvolverem como cidades sustentáveis ${ }^{11}$, afinal, as boas práticas destinadas a um crescimento econômico pautado na inclusão e justiça social e na preservação ao meio ambiente para as presentes e futuras gerações são necessárias. Assim, os moradores das cidades passam a se adaptar aos progressos como, por exemplo, a mobilidade urbana, a qual pode substituir os veículos motorizados pelo uso de transporte coletivo ou mesmo bicicletas, com a consequente ampliação das ciclovias, como tem acontecido em Brasília. Com esse incentivo do Poder Público o trânsito passa a fluir, as pessoas terão melhores condições de vida e haverá a redução de riscos ambientais (poluição) (GOVERNO FEDERAL, 2014).

Diante da expansão e incentivo da prática desenfreada do consumo, observa-se a existência de empresas voltadas para os mais diversos nichos de mercado, seja o de pesca, de extração de petróleo, de produção de produtos agrícolas e industriais, dentre outros. No entanto, além da apreensão dos recursos naturais sem o interesse de serem repostos à natureza, tais empresas os detêm como se fossem sua posse e fruto da sua produção, por vezes não respeitando a época do defeso, na piscicultura, ou o limite de extração da água na produção da soja, por exemplo. Por isso, os recursos disponíveis pela natureza e explorados comercialmente devem ser fiscalizados, cuidados e utilizados racionalmente (DOWBOR, 2008, p. 64).

A percepção diante disso tudo sintetiza a vontade do ser humano em deter o poder e dominar as relações sociais. Aliás, Marina afirma, “[...] Si no hubiera deseos, o al menos, si no hubiera deseos encontrados, no existiría el poder [...]”, logo, constata-se que há paralelamente o desejo de poder e o poder de desejo. Por vezes, o "poderoso" tem a sensação e o pensamento de estar alcançando o bem para todos, no entanto, a própria história comprova que os mais famosos líderes, chamados pelo autor de assassinos políticos, tinham a concepção de estar guiando o povo à felicidade $(2009$, p. $16 ; 21)$.

\footnotetext{
${ }^{11}$ Para Boff, o termo sustentabilidade se refere a "[...] toda ação destinada a manter as condições energéticas, informacionais, físico-químicas que sustentam todos os seres vivos, especialmente a Terra viva, a comunidade de vida e a vida humana, visando sua continuidade e ainda atender as necessidades da geração presente e das futuras, de tal forma que o capital natural seja mantido e enriquecido em sua capacidade de regeneração, reprodução e coevolução". (2012, p. 107).
} 
A concretização do Estatuto da Cidade transmite segurança jurídica aos indivíduos, isso porque o mesmo determina os "princípios gerais" a serem aplicados em âmbito local visando a qualidade de vida da coletividade. Igualmente, os mecanismos de participação popular incluídos nessa Lei têm como finalidade aproximar governantes e governados, promovendo o diálogo para a construção do Plano Diretor, por exemplo (ANTUNES, 2010, p. 331-333). Jacobi discorre sobre a imprescindibilidade de haver a troca de conhecimentos, sugestões e apontamentos quando o assunto trata da sustentabilidade:

\begin{abstract}
Assim, a idéia [sic] de sustentabilidade implica na prevalência da premissa de que é preciso estabelecer uma limitação definida nas possibilidades de crescimento e um conjunto de iniciativas que levem em conta a existência de interlocutores e participantes sociais relevantes e ativos através de práticas educativas e de um processo de diálogo informado, o que reforça um sentimento de coresponsabilização e de constituição de valores éticos. Isto também implica em que uma política de desenvolvimento na direção de uma sociedade sustentável não pode ignorar nem as dimensões culturais, nem as relações de poder existentes e, muito menos, o reconhecimento das limitações ecológicas, sob pena de apenas manter um padrão predatório de desenvolvimento (1999, p. 42).
\end{abstract}

O município precisa estimular a participação dos seus habitantes, pois só assim terá conhecimento sobre as circunstâncias da sua rua, do seu bairro, enfim, da localidade aonde vive. Cita-se como exemplo, a iniciativa da Prefeitura de Passo Fundo/RS juntamente com a Universidade de Passo Fundo em provocar a comunicação entre cidadãos e governantes com a efetivação do projeto "Plano Municipal de Saneamento Básico Passo Fundo", baseado na Lei n 11.445/2007 (Lei do Saneamento Básico), com o objetivo de propiciar uma maior interação da comunidade "em todo o processo de elaboração e implementação" desse Plano (PREFEITURA MUNICIPAL DE PASSO FUNDO, 2014).

Portanto, após ter sido examinada a possibilidade da construção de cidades sustentáveis a partir da iniciativa do Poder Público e da colaboração dos cidadãos, avalia-se a necessidade da otimização de políticas públicas direcionadas à educação ambiental de crianças e adolescentes como uma estratégia de conscientização para reduzir os danos à natureza e aos indivíduos.

\title{
3 PODER LOCAL E EDUCAÇÃO AMBIENTAL
}


No decorrer da pesquisa foi confirmada a conexão existente entre o sujeito social e a natureza, logo, a prática consumista exacerbada tem a capacidade de causar e agravar os danos ambientais. Assim, acredita-se que a partir da divulgação de informações por parte do Poder Público os cidadãos passarão a compreender os riscos e construir juntos alguns caminhos para transformar esse cenário.

Nesse contexto, as cidades têm a atribuição de proporcionar aos indivíduos uma boa qualidade de vida, sendo orientadas pelo Poder Executivo Municipal, o qual se mostra altamente qualificado e responsável para organizar e proporcionar a participação dos cidadãos no processo de formação das tutelas jurídicas e políticas em âmbito local. Nesse sentido, os municípios são considerados "[...] como referência de cultura e cidadania, tornando-se importante espaço estratégico de atuação para a salvaguarda dos valores e interesses daqueles que residem nestes territórios”, esclarecem Hermany e Rodembusch (2010, p. 86-87). Para Dowbor,

\begin{abstract}
Defender os interesses do município é promover o desenvolvimento equilibrado, com uma base econômica variada, e uma situação social mais justa. Trata-se de promover uma visão de longo prazo, entendendo-se que o município, o bairro ou ainda um vale numa área rural será o lugar de vida dos filhos, dos netos, a quem é preciso deixar algo melhor: é este problema que enfrentamos (2008, p. 59).
\end{abstract}

Com a descentralização do poder instituída na Constituição Federal de 1988, os municípios passaram a ter autonomia política, administrativa, financeira e legislativa no federalismo brasileiro, tornando-se hábeis a concretizar os direitos dos cidadãos, solucionando os anseios populares e não satisfazendo somente as vontades das elites políticas. Nesse aspecto, para a concretização das políticas públicas, os indivíduos devem participar e controlar os atos de gestão. (HERMANY; RODEMBRUSH, 2010, p. 88-89)

No entanto, importa ressaltar a opinião de Schmidt, o qual acredita que, com a promulgação da Constituição Federal de 1988 e consequentemente a adoção do regime democrático com ampla autonomia política aos entes federativos, houve um impasse para o contexto político do país, qual seja, "a descontinuidade administrativa" - decorrente da troca constante dos representantes políticos. Essa situação possui prós e contras, podendo desenvolver renovação e progresso, como também acarretar a desistência do desenvolvimento de algumas políticas ou a construção de outras (2008, p. 2307-2333). 
Sobre a descontinuidade administrativa e a descontinuidade das políticas de governo, Jacobi faz menção à quebra do "círculo vicioso" dos gestores que desejam eternizar-se no poder, assim:

\begin{abstract}
O tema dos resíduos sólidos é provavelmente aquele que melhor exemplifica as possibilidades de formulação de políticas públicas minimizadoras ou preventivas. Entretanto, a timidez das iniciativas e a descontinuidade das políticas têm criado um verdadeiro círculo vicioso pautado pela lógica da paralisia, e o enfrentamento através de práticas alternativas da lógica do status quo. Diversas experiências bem sucedidas de gestão a partir de práticas alternativas mostram que é possível romper com o círculo vicioso existente e engajara população em ações pautadas pela coresponsabilização e compromisso com a defesa do meio ambiente a partir de interdependências com os setores de saúde e educação (1999, p. 46, grifo do autor).
\end{abstract}

O vínculo desenvolvido entre o município e o cidadão cria direitos e deveres recíprocos entre ambos, assim o Poder Público trabalha “[...] ou cobrando dos cidadãos seus impostos, ou prestando-lhes serviços públicos de transporte, educação ou saúde, ou até restringindo a liberdade se algum crime fizer", analisa Costa (2014, p. 368). A renovação da política possibilita ao cidadão controlar seus governantes e fazer parte tanto da formação quanto do controle das políticas públicas municipais, devendo ser decididas em conjunto com a população.

Para formar indivíduos e comunidades comprometidas com os interesses e demandas locais, a educação foi identificada como um fator ímpar. Historicamente o seu reconhecimento se deu a partir do século XX, constando na legislação nacional o direito de todos à educação. Entretanto, não se deve ter o pensamento extremista de encontrar na educação a solução para todos os desafios contemporâneos. (GORCZEVSCKI, 2010, p. 39$40 ; 43)$

Nesse sentido, para a presente pesquisa, a criação de políticas públicas educacionais passa a ser uma das estratégias para fomentar a participação da cidadania em nível local, aproximando governados e governantes a fim de alcançar o bem-comum, bem como fiscalizar as políticas públicas para evitar a propagação de danos ambientais. Segundo Morin, "É necessário introduzir a crise da educação em um contexto crísico mais vasto, que comporte não apenas a consideração da cultura juvenil e da situação atual da juventude, mas o conjunto dos problemas de sociedade e de civilização dos quais estão imersos os problemas da educação" (2015. p. 65). 
Mesmo na presença de quem acredite que a educação não tem a propriedade para superar todos os desafios e empecilhos, Santin combate esse entendimento pessimista, explicando a relevância da educação para democratizar o espaço público, assim:

[...] É preciso potencializar a escola com um instrumento de fortalecimento da sociedade civil, capacitando aqueles que não participam do poder a também fazer parte dele, agindo conjuntamente com seus representantes locais na melhoria das condições de sua rua, de seu bairro, de sua cidade ou região. Não se trata de prescindir do Estado, mas sim atuar dentro dele, democratizando as instituições tradicionais de poder (2017, p. 184).

Quanto à existência da crise da educação, importa salientar que o ser humano também está inserido em outras crises, quais sejam, da "civilização", da "sociedade", da "democracia", da "econômica". Tal situação leva a crer que se trata de um ciclo vicioso de crise, onde uma depende das outras, assim como a crise da educação (MORIN, 2015, p. 65).

A Lei $n^{\circ}$ 9.795/1999 regulamenta e dispõe sobre a educação ambiental, instituindo a Política Nacional de Educação Ambiental, com vistas a orientar como se desenvolverá a política educacional em benefício da conservação do meio ambiente, da melhoria de vida e da sustentabilidade do país. ${ }^{12}$ Inclusive, a previsão legal está de acordo em estipular políticas públicas com enfoque à educação ambiental em todos os níveis de ensino (BRASIL, LEI N ${ }^{\circ}$ $9.795,1999){ }^{13}$

Porém, não bastam apenas mecanismos legais. É importante ressaltar o cunho social e cultural advindo da educação, a qual vem sendo tratada como mero produto de mercado pela humanidade. Na concepção de Santin:

[...] É a educação a responsável por formar o indivíduo para a vida, torná-lo plenamente livre, autônomo e responsável pela sua história pessoal e social. Mas tem se observado em vários momentos da história brasileira arautos reformistas ditarem mudanças na configuração do processo de ensino a fim de se conformar com as exigências tecnicistas do mercado econômico (2017, p. 185).

\footnotetext{
${ }^{12}$ Lei $n^{\circ}$ 9.795/1999: Art. $1^{\circ}$ - Entendem-se por educação ambiental os processos por meio dos quais o indivíduo e a coletividade constroem valores sociais, conhecimentos, habilidades, atitudes e competências voltadas para a conservação do meio ambiente, bem de uso comum do povo, essencial à sadia qualidade de vida e sua sustentabilidade.

${ }_{13}^{13}$ Lei $n^{\circ} 9.795 / 1999$, Art. $3^{\circ}$ - Como parte do processo educativo mais amplo, todos têm direito à educação ambiental, incumbindo: I - ao Poder Público, nos termos dos arts. 205 e 225 da Constituição Federal, definir políticas públicas que incorporem a dimensão ambiental, promover a educação ambiental em todos os níveis de ensino e o engajamento da sociedade na conservação, recuperação e melhoria do meio ambiente;
} 
A escola exerce papel fundamental para os estudantes e cumpre a ela definir matérias que permitam a construção do senso crítico e o entendimento dos desafios vivenciados na contemporaneidade. A essência da cidadania está na abertura de espaço para a comunicação e na troca de ideias entre sujeitos sociais, induzindo à incorporação de uma educação revestida de diálogo sem preconceitos (SANTIN, 2017, p. 187).

Observando alguns países que adotam a participação popular de crianças nos municípios, a Prefeitura Municipal de Passo Fundo criou um projeto ${ }^{14}$ chamado Cidade do Amanhã, o qual prevê a interlocução entre gestores e crianças para auxiliar na Revisão do Plano Diretor. Com as atividades interativas realizadas com as crianças - jogos de perguntas e respostas, ilustrações, maquetes, entre outros - foi possível verificar as deficiências do município, incluindo desde o bairro que reside a criança até a escola, por exemplo. (PREFEITURA MUNICIPAL DE PASSO FUNDO, 2017).

\begin{abstract}
Com isso, a participação comunitária, que antigamente era vista como uma prática vanguardista, hoje é amplamente conhecida, e os esforços para que a participação de crianças e jovens aconteça tem sido maiores do que nunca. Tal participação tem transformado o papel das decisões de planejamento, e agora são também direcionadas às crianças e jovens em um nível local (PREFEITURA MUNICIPAL DE PASSO FUNDO, 2017).
\end{abstract}

Para tanto, cabe aos municípios proteger aquilo que deriva da natureza, observados os recursos que não se renovam ou demoram muito tempo para se renovar, como por exemplo as florestas. Inclusive, existem os recursos naturais "[...] com custos elevadíssimos (no caso da água poluída ou da terra esgotada). A destruição da fauna ou dos recursos pesqueiros é também, em geral, definitiva [...]", o que de fato, leva ao seu esgotamento, alega Dowbor (2008, p. 63).

A reconstrução do espaço público a partir de cidades sustentáveis possibilitará a aproximação de governantes e governados, facilitando o compartilhamento de informações e a preservação do meio ambiente. Portanto, o Poder Local, pautado nas práticas participativas em âmbito municipal ou regional, ao incluir a educação nas diretrizes de políticas públicas busca prevenir danos tanto para a natureza quanto para as próximas gerações. E nesse sentido,

\footnotetext{
14 “O projeto foi organizado a partir de atividades realizadas por etapas e em dias diferentes, baseando-se em um estudo de caso patrocinado pela UNICEF e nos métodos de pesquisas feitas anteriormente, culminando em uma exposição final dos resultados, que farão parte da etapa de diagnóstico a constar na revisão do Plano Diretor. As atividades serão realizadas com alunos dos $3^{\circ}$ e $4^{\circ}$ anos do ensino fundamental, entre 9 e 10 anos" (PREFEITURA MUNICIPAL DE PASSO FUNDO, 2017).
} 
pode-se partir de experiências positivas de outros países, onde tornou-se possível compreender os benefícios dessa estratégia:

Por meio da educação ambiental para crianças e jovens e do estímulo da participação deles no processo de desenvolvimento da cidade, Helsingborg promove a sustentabilidade. Ao elevar a conscientização e o engajamento desse público em temas ambientais, a Oficina de Meio Ambiente e o Projeto Campus Escola Sustentável contribuem para o Desenvolvimento Local Sustentável (PROGRAMA CIDADES SUSTENTÁVEIS, 2005).

Portanto, o Poder Público possui a importante função de conscientizar os indivíduos dos riscos que o consumo exacerbado acarreta para todos indistintamente, estimulando práticas sustentáveis. Afinal, diante da evolução dos tempos e, consequentemente, do fácil acesso aos meios de consumo, considera-se a conservação do meio ambiente e dos recursos naturais um dos principais desafios deste século.

\section{CONSIDERAÇÕES FINAIS}

Como visto, esse artigo propôs analisar a reconstrução do Poder Local a partir da iniciativa dos governantes e governados em criar políticas públicas participativas e voltadas à educação ambiental nos municípios, especialmente para crianças e adolescentes. Com a elaboração e aplicação de novas ideias, as cidades estarão conservando o meio ambiente e tendo a oportunidade de criar metas sustentáveis para o futuro em conformidade com o disposto pelo Estatuto da Cidade.

O índice de danos ambientais tem aumentado, muitos deles decorrentes dos hábitos irrefreáveis de consumo, isso porque o mercado cria produtos interessantes e inovadores visando o lucro sem, no entanto, pensar nas consequências negativas que este consumo desenfreado tende a originar. Com isso, percebe-se o importante papel que os sujeitos sociais exercem nas relações contemporâneas, daí a ideia de o Poder Público, em especial do espaço local, estimular a conscientização e a preservação da natureza.

As necessidades humanas aproximam o cidadão dos produtos oferecidos pela indústria, tornando o consumo um mecanismo benéfico para o crescimento econômico e para a manutenção da estabilidade das moedas, dos níveis de emprego e do mercado em si. Por isso, em pleno século XXI a degradação ambiental é constante e o desafio maior se resume 
em controlar e estipular limites para a extração desses recursos e para a produção dos resíduos.

Certamente o comportamento do ser humano deve ser reavaliado, para isso o Poder Local tem a possibilidade de implementar políticas públicas educacionais visando o bem da sociedade e do meio ambiente para as presentes e futuras gerações. Cumpre ressaltar que os recursos naturais têm sido utilizados demasiadamente e muitas vezes não são repostos, desestabilizando ainda mais a conexão entre o indivíduo e a natureza.

Pelo exposto, observando o cenário atual, percebe-se a imprescindibilidade da atuação positiva dos municípios, otimizando políticas públicas educacionais de modo a informar e esclarecer como a vida em sociedade pode se tornar melhor e mais equilibrada. Assim, as cidades educadoras e sustentáveis podem ser uma alternativa inovadora e inteligente para aproximar cidadãos e governantes para juntos alcançarem melhorias e evitarem os riscos ambientais.

\section{REFERÊNCIAS}

ANTUNES, Paulo de Bessa. Direito ambiental. 12. ed. Rio de Janeiro: Lumen Juris, 2010.

ARENDT, Hannah. A condição humana. 10. ed. Rio de Janeiro: Forense Universitária, 2007.

ARISTÓTELES, Ética a Nicômaco. São Paulo: Martin Claret, 2004.

BAUDRILLARD, Jean. A sociedade de consumo. Rio de Janeiro: Elfos Ed.; Lisboa: Edições 70, 1995.

BAUMAN, Zygmunt. Vida para consumo: a transformação das pessoas em mercadorias. Rio de Janeiro: Jorge Zahar Ed., 2008.

BOFF, Leonardo. Sustentabilidade: o que é - o que não é. Petrópolis, RJ: Vozes, 2012.

BRASIL. Constituição (1988). Constituição da República Federativa do Brasil. Brasília, DF: Senado, 1988. Disponível em:

http://www.planalto.gov.br/ccivil_03/constituicao/constituicaocompilado.htm. Acesso em: 02 set. 2018.

Lei $\mathbf{n}^{0}$ 9.795, de 27 de abril de 1999. Disponível em:

https://www.planalto.gov.br/ccivil_03/leis/19795.htm. Acesso em: 02 set. 2018. 
Lei $\mathbf{n}^{\mathbf{0}}$ 10.257, de 10 de julho de 2001. Disponível em:

http://www.planalto.gov.br/ccivil_03/leis/leis_2001/110257.htm. Acesso em: 02 set. 2018.

COSTA, Nelson Nery. Direito municipal brasileiro. 6. ed. Rio de Janeiro: Forense, 2014.

CRUTZEN, P. Geology of mankind: the Anthropocene. Nature, v. 415, p. 23-25, 3 jan. 2002. Disponível em: http://www.geo.utexas.edu/courses/387H/PAPERS/Crutzen2002.pdf. Acesso em 05 set. 2018.

DEMO, Pedro. Participação é conquista: noções de política social participativa. 2. ed. São Paulo: Cortez, 1993.

DOWBOR, Ladislau. O que é poder local. São Paulo: Brasiliense, 2008.

FREUD, Sigmund. O mal-estar na civilização. Rio de Janeiro: Imago, 1997.

GORCZEVSKI, Clóvis. A educação para os direitos humanos como política pública de combate a violência na sociedade pós-moderna. In: GORCZEVSKI, Clóvis. Direitos humanos e participação política. Porto Alegre: Imprensa Livre, 2010.

GOVERNO FEDERAL. Cidades sustentáveis reduzem impactos ambientais. 2014. Disponível em: <http://www.brasil.gov.br/meio-ambiente/2014/12/cidades-sustentaveisreduzem-impactos-ambientais> Acesso em: 27 fev. 2018.

HARVEY, David. O enigma do capital e as crises do capitalismo. Tradução de João Alexandre Peschanski. São Paulo: Boitempo, 2011.

HERMANY, Ricardo; RODEMBUSCH, Claudine Freire. O empoderamento dos setores da sociedade brasileira no plano local na busca de implementação de políticas públicas sociais. In: HERMANY, Ricardo. Empoderamento Social Local. Santa Cruz do Sul: Editora IPR, 2010.

JACOBI, Pedro. Poder Local, Políticas Sociais e Sustentabilidade. Saúde e Sociedade. São Paulo, 8 (1):31-48, 1999.

LATOUCHE, Serge. Pequeno tratado do decrescimento sereno. Tradução de Cláudia Berliner. São Paulo: Martins Fontes, 2009.

MARINA, José Antonio. La pasión del poder: teoría y práctica de la dominación. Barcelona: Anagrama, 2009.

MORIN, Edgar. Ensinar a viver: manifesto para mudar a educação. Porto Alegre: Sulina, 2015.

PREFEITURA MUNICIPAL DE PASSO FUNDO. Plano Municipal de Saneamento Básico Passo Fundo. Disponível em: http://pmsb.upf.br/index.php/participacao-dacomunidade. Acesso em: 05 set. 2018. 
PREFEITURA MUNICIPAL DE PASSO FUNDO. Revisão do Plano Diretor: Cidade do Amanhã. Disponível em: http://www.pmpf.rs.gov.br/secao.php?t=11\&p=797. Acesso em: 05 set. 2018.

PROGRAMA CIDADES SUSTENTÁVEIS. Educação ambiental e participação no Desenvolvimento Local Sustentável. 2005. Disponível em:

http://www.cidadessustentaveis.org.br/boas-praticas/educacao-ambiental-e-participacao-nodesenvolvimento-local-sustentavel. Acesso em: 02 set. 2018.

RULL, V. The "Anthropocene" uncovered. Collectanea Botanica, v. 36, enero-diciembre 2017. ISSN-L: 0010-0730. http://dx.doi.org/10.3989/collectbot.2017.v36.008. Disponível em: http://collectaneabotanica.revistas.csic.es/index.php/collectaneabotanica/article/view/254/318. Acesso em 05 set. 2018.

SANTIN, Janaína Rigo. Estado, constituição e administração pública no século XXI: novos desafios da cidadania e do poder local. Belo Horizonte: Arraes Editores, 2017.

SCHMIDT, João Pedro. Para entender as políticas públicas: aspectos conceituais e metodológicos. In: LEAL, Rogério Gesta Leal; REIS; Jorge Renato. Direitos sociais e políticas públicas: desafios contemporâneos. Tomo 8, Santa Cruz do Sul: EDUNISC, 2008. p. 2307-2333.

SEN, Amartya. As pessoas em primeiro lugar: a ética do desenvolvimento e os problemas do mundo globalizado. Amartya Sen e Bernardo Kliksberg: Tradução Bernardo Ajzemberg e Carlos Eduardo Lins da Silva. São Paulo: Companhia das letras, 2010. 